\title{
PATTERN OF PRESENTATION OF GUILLAIN-BARRE SYNDROME IN THREE TERTIARY LEVEL HOSPITAL IN BANGLADESH
}

\author{
Kabir ATMH ${ }^{1}$, Rahman $\mathrm{M}^{2}$, Ali B ${ }^{3}$, Kabiruzzaman $^{4}$, Ahmad M $^{5}$
}

\begin{abstract}
Introduction: Guillain-Barre syndrome (GBS) is an acute frequently severe and fulminating peripheral neuropathy that is autoimmune in nature. It occurs at a rate of between 1 and 4 per $1,00,000$ cases annually. In the United States, 5000-6000 cases occur per year. Males are at slightly higher risk of developing GBS than females and in western countries, adults are more frequently affected than children.
\end{abstract}

Objective: This study was carried out to observe the pattern of presentation of GBS among Bangladeshi population.

Methods: This is an observational longitudinal study done in Combined Military Hospital (CMH), Bangobandhu Sheikh Mujib Medical University (BSSMU) and National Institute of Neuroscience Hospital (NINS) during the period of January 2010 to June 2012. A total number of 50 GBS patients were included in this study.

Results: A total of 50 patients were studied, the mean age of the patients was $30.40 \pm 1.56$ and male was found predominant. About $80 \%$ of the patients presented with the typical pattern of Landrys are ascending paralysis, $12 \%$ had bulbar involvement first and the rest $8 \%$ had mixed presentation, $56 \%$ patients had facial nerve involvement and $16 \%$ patients had bulbar cranial nerve involvement. About $62 \%$ patients presented with pain and paresthesia though none had any abnormality in pain, touch and temperature sensation but $10 \%$ patients had position sense and $50 \%$ had some degree of vibration sense abnormality. Ten patients had respiratory muscle weakness requiring Intensive Care Unit (ICU) support. All patients had acute flaccid type of paraplegia or quadriplegia having hyporeflexia or areflexia (mostly). About $56 \%$ patients had autonomic involvement but none had sphincter disturbance. On electrophysiology, 56\% patients had demyelination type of nerve injury, $36 \%$ had mixed and $8 \%$ had axonal type of nerve injury.

Conclusion: The pattern of presentation of GBS cases was not much variable and was found to be the studies done before.

Key-words: Guillain-Barre syndrome (GBS), Cerebrospinal Fluid (CSF), Intensive Care Unit (ICU).

\section{Introduction}

A leading cause of acute flaccid paralysis in much of the world is acute paralytic neuropathy diagnosed clinically as the Guillain-Barre syndrome $(\mathrm{GBS})^{1}$. Patients with GBS and related variants suffer from an acute onset of autoimmune neuropathy. GBS is characterized by symmetrical ascending flaccid paralysis, areflexia and albumino-cytological dissociation in cerebrospinal fluid (CSF) ${ }^{2}$. It is diagnosed by the history and typical neurological findings. The characteristic nerve conduction study, increased CSF protein and serological evidence of antecedent infection help in the diagnosis ${ }^{3}$. Patients may initially present with paresthesia or sensory symptoms with weakness or weakness alone.

1. Lt Col ATM Humayun Kabir, MBBS, FCPS, FCPS, Medical specialist \& Neurologist, CMH, Dhaka; 2. Col Mozibor Rahman, MBBS, FCPS, Classified Spl in Medicine \& Neurology, CMH, Dhaka; 3. Dr. Bahadur Ali, MBBS, MD, Assoc Prof of Neurology, BSSMU, Dhaka; 4. Dr. Kabiruzzaman, MD, Medical Officer, National Institute of Neuroscience and Hospital, Dhaka; 5. Lt Col Mushtaq Ahmad, MBBS, DFM, MCPS, FRSPH, Assoc Prof \& Head of the Dept of Forensic Medicine \& Toxicology, AFMC, Dhaka. 
The fairly symmetrical weakness of the lower limbs ascending proximally over hours to days to involve the arm, facial and oropharyngeal muscles and in severe cases, respiratory muscles. Proximal as well as distal muscles of the limbs are involved, usually lower extremities before the upper (landry's ascending paralysis). Less often weakness may begin in proximal or cranial nerve innervated muscles. Its severity varies from mild involvement, in which the patients are still capable of walking unassisted to severe involvement like quadriplegia, hyporeflexia or areflexia. The progression ends by 1-4 weeks of the illness. Cranial nerve involvement occurs in about $45-75 \%$ of cases in which bilateral facial weakness is mostly seen. Involvement of the extraocular and lower cranial nerves is seen less often. Pseudotumor cerebrae or papilloedema occur as a rare complication. Respiratory muscle involvement requiring artificial ventilation seen in $10-20 \%$ of patients ${ }^{4}$. Sensory loss is not a prominent feature and is limited frequently to distal impairment of vibration sense, moderate to severe pain occurs in $85 \%$ of patients. Burning and tingling dysesthesia is present in about half of the patients whereas myalgic limb pain associated with joint stiffness is seen less ${ }^{5}$. Autonomic dysfunction either in the form of decreased or increased sympathetic or parasympathetic activity is seen in about $65 \%$ of cases ${ }^{4,5,6}$.

\section{Materials \& Methods}

This is an observational longitudinal control study done in $\mathrm{CMH}$, BSMMU, NINS, Dhaka, during the period of July 2011 to June 2013. A total number of 50 GBS patients admitted into the above mentioned places were included in the study. The criteria for selection of the patients were (a) typical history of acute onset of polyneuropathy (b) either sex (c) age between 10-60 years (d) patients of both rural and urban areas \& (e) patients with positive nerve conduction study and CSF findings consistent with albumin cytological dissociation.

\section{Results}

A total of 50 cases were selected for this study and the clinical findings found are furnished in the following tables.
Table-I: Age distribution of the cases $(n=50)$.

\begin{tabular}{|l|c|}
\hline Age of the patients & Cases \\
\hline $10-19$ yrs & $4(8 \%)$ \\
\hline $20-29$ yrs & $22(44 \%)$ \\
\hline $30-39$ yrs & $15(30 \%)$ \\
\hline $40-49$ yrs & $7(14 \%)$ \\
\hline $50-59$ yrs & $2(4 \%)$ \\
\hline
\end{tabular}

(Mean \pm SD) was $30.40 \pm 1.56$ yrs

Table-II: Sex distribution of the cases $(n=50)$.

\begin{tabular}{|l|c|}
\hline Age of the patients & No of cases \\
\hline Male & $33(66 \%)$ \\
\hline Female & $17(34 \%)$ \\
\hline
\end{tabular}

Table-III: Types of preceding illness $(n=35)$.

\begin{tabular}{|l|c|}
\hline Preceding illness (1-4 weeks before) & No of cases \\
\hline Respiratory tract infection (RTI) & $29(85 \%)$ \\
\hline Diarrhea & $4(10 \%)$ \\
\hline Surgery & $2(5 \%)$ \\
\hline
\end{tabular}

Table-IV: Pattern of development of weakness $(n=50)$.

\begin{tabular}{|l|c|}
\hline Pattern of weakness & No of cases \\
\hline Ascending paralysis & $40(80 \%)$ \\
\hline Oropharyngeal or other cranial nerves & $6(12 \%)$ \\
\hline Other patterns & $4(8 \%)$ \\
\hline
\end{tabular}

Table-V: Involvement of cranial nerves (CN) $(n=50)$.

\begin{tabular}{|l|c|}
\hline Pattern of weakness & No of cases \\
\hline Cranial nerve VII & $28(56 \%)$ \\
\hline Bulbar & $8(16 \%)$ \\
\hline Extra ocular & $0(0 \%)$ \\
\hline
\end{tabular}

\section{Discussion}

GBS can occur in any age group. In the study the mean age of patients was $30.40 \pm 1.56$. It coincides with the study done before by Haque et al $(1998)^{7}$, Rees, Thomson et al $(1998)^{8}$, Hankey et al (i997) ${ }^{9}$, and Seneviratne $(2000)^{10}$. In our study 66 percent of cases were male and 34 percent were female. This male preponderance in the GBS patients coincides with the study of Seneviratne $(2000)^{10}$ and Mc Clean, Jacob et al $(1994)^{11}$. About $70 \%$ of cases had history of preceding illness, of them $85 \%$ had Respiratory Tract Infection (RTI), 
$10 \%$ had gastroenteritis \& $5 \%$ had surgery. This finding is consistent with the studies by Wirner, Hughes, Anderson etal $(1980)^{12}$ and Ho et al $(1995)^{1}$. About $80 \%$ of the case group presented with ascending paralysis, $12 \%$ presented with oropharyngeal weakness first and the rest $8 \%$ did not follow any typical feature. About $56 \%$ patients had facial nerves involvement principally bilaterally and $16 \%$ had bulbar cranial nerves involvement. Only $10 \%$ cases developed bulbar muscle weakness in the form of dysphonia and/or dysphagia. None had ophthalmoplegia or papilloedema. This is consistent with the study of Asbury and Cornblath (1990) ${ }^{13}$.

About $62 \%$ patients initially presented with pain and paresthesia but none had any pain, touch and temperature sensation abnormality on examination. Ten percent had some degree of position and $50 \%$ of the patients had vibration sense abnormality. About $20 \%$ of the patients had respiratory muscle weakness requiring ICU support. These findings are consistent with the studies of Winer, Hughes, Osmon et al (1998) $)^{14}$. All the patients had flaccid type of motor weakness from grade 0 to grade 3 muscle power. There was wasting of muscles in $16 \%$ of cases and all had either areflexia or hyporeflexia, half of the patients had flexor plantar response and half had no response at all; none had any sphincter disturbance.

About $56 \%$ of the patients had autonomic disturbance, $16 \%$ had hypotension, $4 \%$ hypertension, $20 \%$ tachycardia, $4 \%$ bradycardia and $12 \%$ had some degree of trophic changes which are consistent with the studies of Bosch and Smith $(2000)^{15}$. Electro-physiologic examination revealed that $56 \%$ had demyelization, $36 \%$ had mixed and $8 \%$ had axonal pattern of nerve injury. These findings are consistent with the studies of Asbury \& Corrblath (1990) ${ }^{13}$ and Gordon \& Will born $(2000)^{16}$. Electromyelography was not done in any case.

\section{Conclusion}

GBS is not an uncommon disease in our country. Although this study was carried out in three tertiary level hospitals, the pattern of presentations of GBS cases was not much variable and were consistent with the studies done before. A large scale study may be done for further evaluation.

\section{References}

1. Ho TW, Mishu B, Li CY, Gao CY, Cornblath DR, Griffin JW, et al. Guillain-Barre syndrome in northern China: relationship to Campylobacter jejuni infection and anti-glycolipid antibodies. Brain 1995; 118: 597-605.

2. Guillain G, Barre JA, and Strohl A. Sur un syndrome de radiculonevrite avec hyperalbuminose du liquide cephalorachidien sans reaction cellulaire Bull. Soc Med Hop Paris 1916; 40: 1462-70.

3. Rees JH, Soudain SE, Gregson NA. Campylobacter jejuni infections and Guillain-Barre syndrome. N Engl J Med 1995; 333:1374-9.

4. Bosch EP, Smith BE. Disorders of peripheral nerves. In Bradley WG, Daroff RB, Fenichee GM, Marsden CD, editors. Neurology in clinical practice. Vol II, 3rd ed. Oxford: Butterworth-Heinemann, 200: pp.2045-130

5. Moulin DE, Hagen N, FeasyTE. Pain in Guillain- Barre syndrome. Neurology 1997; 48: 328-31.

6. Zochoduc DW. Autonomic involvement in Guillain-Barre syndrome: a review. Muscle Nerve 1994; 17: 1145-55.

7. Haque MA, Haque S, Rahman MA, Hossain S, Gosh PK, Begum T, et al. Presentation of GBS- a prospective study in BIRDEM Hospital. Bangladesh J Neurosci 1998; 14:35-40.

8. Ress JH, Thompson RD, Smeeton NC, Hughes RAG Epidemiological study of Guillain-Barre syndrome in South East England. J Neurol Neurosurg Psychiatry 1998; 64 74-7.

9. Hankey GJ. Guillain-Barre syndrome in Western Australia, 1982-85. Med J Aust 1987; 146: 130-3.

10. Seneviratne U. Guillain-Barre syndrome. Postgrad Med $J$ 2000; 76: 774-82.

11. Mc Lean $M$, Duclos $P$, Jacob $P$. Incidence of Guillain-Barre syndrome in Ontario and Quebec, 1983-89, using hospital service data bases. Epidemiology 1994; 5:443-8.

12. WinerJB, Hughes RAC, Anderson MJ. A prospective study of acute idiopathic neuropathy,ll Antecedent events. J Neurol Neurosurg Psychiatry 1988,51:613-8.

13. Asbury Ak, Cornblath DR. Assessment of current diagnostic criteria for Guillain-Barre syndrome. Ann Neurol 1990; 27 (suppl):21 -4.

14. WinerJB, Hughes RAG, Osmond G. A prospective study of acute idiopathic neuropathy. I. Clinical features and their prognostic value. J Neurol Neurosurg Psychiatry 1998; 51: $605-12$

15. Bosch EP, Smith BE. Disorders of peripheral nerves. In Bradley WG, Daroff RB, Fenichee GM, Marsden CD, editors. Neurology in clinical practice. Vol II, 3rd ed. Oxford: Butterworth-Heinemann, 200: pp.2045-130.

16. Gordon PH, Wilbourn AJ. Early electrodiagnostic findings in Guillain-Barre syndrome. Arch Neuro 2001;58:913-7. 